\title{
Potentialities of hydrogen enriched natural gas for residential heating decarbonization and impact analysis on premixed boilers
}

\author{
Fabio Schiro, ${ }^{1, *}$, Anna Stoppato $^{1}$, and Alberto Benato ${ }^{1}$ \\ ${ }^{1}$ University of Padova, Department of Industrial Engineering, Via Venezia n.1, Padova, \\ Italy
}

\begin{abstract}
Nowadays, decarbonization of energy economy is a topical theme and several pathways are under discussion. Gaseous fuels will play a primary role during this transition, and the production of renewable or low carbon-impact gaseous fuels is necessary to deal with this challenge. Decarbonization will be sustained by an increasing share of renewables, which production intermittency can be critical for the energy system. Renewable hydrogen generation is a viable solution since this energy vector can be produced from electricity with a fast response and injected in the existing natural gas infrastructures, granting storage capacity and easy transport. Parallelly to the renewable-based energy production, fossil-based energy can be exploited with a low carbon impact, using methane from reservoirs to produce hydrogen capturing $\mathrm{CO}_{2}$. The mentioned scenarios will lead to hydrogen enrichment of natural gas, which impact on the infrastructures is being actively studied. The effect on end-user devices, instead, is poorly analysed, but is fundamental to be assessed. This paper highlights the impact on the widely used premixed condensing boilers, which will be fired with hydrogen enriched natural gas in the near future, and the changes required to components.
\end{abstract}

\section{Introduction}

Energy systems are evolving to reduce their environmental impact and face the challenges related to depletion of resources, growing global population and climate change. The future energy systems are expected to be based on clean and renewable sources (RES), able to provide energy with a low $\mathrm{CO}_{2}$ emission. In Europe, local and worldwide agreements pushed the States through low-carbon technologies: Kyoto protocol signed in 1997 and enforced in 2005 by imposing all members to decrease the greenhouse gases emissions, the Climate and Energy Package signed in 2007, the COP21 agreement concluded in Paris in 2015. The target of European decarbonization strategy is to grant $75 \%$ of gross final energy consumption from renewables in 2050. Decarbonization involves electricity supply, thermal energy supply to buildings and industries, and transports. It is known that RES production is less constant and predictable than fossil-based, and an environmentally friendly system

${ }^{*}$ Corresponding author: fabio.schiro@tiscali.it 
based on electricity implies nowadays challenges in the electric grid management and leads to price volatility. Thus, there is a need for novel technologies allowing energy storage and grid balancing, involving an energy carrier with low shipment losses, easy transport and storage. Together with storage and grid balancing technologies, the transition to a cleaner energy system needs a gradual decarbonization of gaseous fuels, that are believed to be still fundamental in the future [1-3]. A promising technology is power-to-gas (P2G), allowing to transform electricity into hydrogen $\left(\mathrm{H}_{2}\right)$, a suitable carrier that can be easily stored in the existing infrastructures and later used as fuel [1]. Together with biogas, $\mathrm{P} 2 \mathrm{G}$ is a low-carbon option based on RES. Another decarbonisation pathway is the transformation of fossil hydrocarbons coupled with carbon capture and sequestration (CCS) [2]. This allows to exploit the huge energy amount contained in natural gas reservoirs, producing $\mathrm{CO}_{2}$ to be captured and $\mathrm{H}_{2}$ to be injected in the fuel supply system. The mentioned scenarios lead to the usage of mixed $\mathrm{H}_{2}$ and natural gas (reported in literature with $\mathrm{H}_{2} \mathrm{NG}$ [3]), to create more environmentally sustainable fuels, and to keep the usage of the existing gas storage and distribution infrastructures. The compatibility of $\mathrm{H}_{2} \mathrm{NG}$ with the current production-to-consumption infrastructures is being studied and assessed with a consistent effort, but the impact of hydrogen addition on the widely used premixed combustion appliances (e.g. condensing boilers) is still poorly analysed [3]. This fact, together with the relevant impact of domestic heating on final energy consumption [4], has driven the Authors to perform this study exploiting their experience on premixed gas fired appliances $[2,3,8,9]$, with the aim to identify the potentialities and challenges related to $\mathrm{H}_{2} \mathrm{NG}$, to suggest the need for re-design of components, and finally to investigate the admissible hydrogen enrichment allowing to keep the today's devices structure. The rest of the paper is organised as follows: in Section 2 a perspective on decarbonisation of residential heating is given, in Section 3 the $\mathrm{H}_{2} \mathrm{NG}$ characteristics are presented and modelled, while in Section 4 the results of the analysis on premixed boilers are presented. Conclusion remarks are given in Section 5.

\section{Residential heating devices: energy consumption, technology and carbon footprint}

The final energy consumption of residential sector in Europe is projected to keep its share up to 2050 , consisting almost the $30 \%$ of the total European energy consumption. The most significant part of this energy ( $65 \%$ in 2010 , projected to be still $58 \%$ in 2050 ) is employed for heating purposes. The share of gaseous fuels in the residential consumption is also not expected to vary significantly up to 2050 [5]. Strategies for decarbonization of residential building energy services must involve the use of less carbon-intensive fuels, the adoption of more energy efficient appliances, the improvement of thermal properties of buildings and the change of energy consumer behaviour. The need for these actions is even more crucial when considering developing countries, whose building energy consumption is expected to reach soon those of developed nations. Building energy request in China is projected to double within this century, while for India the projected increase is fivefold [4]. Said this, any serious action targeting the mitigation of climate change has to include decarbonization of the residential buildings sector. Within this target, decarbonization of gaseous fuels to be used by highly efficient gas fired appliances, such as premixed condensing boilers are, is a very topical research subject. Pathways for the decarbonisation of gaseous fuels involve the injection of hydrogen into the natural gas, via $\mathrm{P} 2 \mathrm{G}$ or via the transformation of fossil hydrocarbons coupled to CCS systems. Power-to-gas is a technological chain involving the conversion of electricity into gas, and its primary step is water electrolysis process taking place in electrolyze cells, whose advantage is also a fast response time. The hydrogen 
produced can be directly injected in the natural gas grid or used to produce renewable methanation process [1]. Transformation of hydrocarbons allows keeping the exploitation of the existing methane reservoirs, potentially with zero carbon impact: in fact, methane can be transformed (for example, by steam methane reforming or thermal dissociation) into $\mathrm{H}_{2}$ and $\mathrm{CO}_{2}$, and the coupling with CCS technologies allow avoiding the release of this last component in the atmosphere [2]. Whichever would be the prevailing decarbonisation pathway, depending also on the evolution of technological and economical aspects $[4,5]$, residential gas fired devices has to be ready to deal in the future with $\mathrm{H}_{2} \mathrm{NG}$.

\section{$3 \mathrm{H}_{2} \mathrm{NG}$ mixtures: peculiarities, modelling, regulatory aspects}

\subsection{Modelling of $\mathrm{H}_{2} \mathrm{NG}$ mixtures}

To allow the subsequent evaluations, the main characteristics of $\mathrm{H}_{2}$ and $\mathrm{CH}_{4}$ have been studied (Table 1), and a modelling of $\mathrm{H}_{2} \mathrm{NG}$ mixture properties and combustion reaction has been implemented.

Table 1. Properties of methane and hydrogen [6].

\begin{tabular}{|c|c|c|}
\hline Property & Methane & Hydrogen \\
\hline Density $\left[\mathrm{kg} / \mathrm{m}^{3}\right]$ & 0.68 & 0.09 \\
\hline Flammable range $[\% \mathrm{vol}]$ & $4.4-17.0$ & $4.0-75.0$ \\
\hline Laminar burning velocity $[\mathrm{m} / \mathrm{s}]$ & 0.4 & 3.1 \\
\hline Minimum spark ignition energy $[\mathrm{mJ}]$ & 0.210 & 0.016 \\
\hline Autoignition temperature $\left[{ }^{\circ} \mathrm{C}\right]$ & 600 & 560 \\
\hline Higher Heating Value $\left[\mathrm{MJ} / \mathrm{m}^{3}\right]$ & 39.8 & 12.7 \\
\hline Lower Heating Value $\left[\mathrm{MJ} / \mathrm{m}^{3}\right]$ & 35.8 & 10.8 \\
\hline
\end{tabular}

Basing on chemical reactions and on equations for gaseous mixtures properties, the volumes of reactants and products are calculated. Equation (1) has been built to describe the combustion reaction for a generic methane/hydrogen mixture, where volumetric hydrogen percentage is indicated with $\mathrm{f}$, and $\lambda$ variable is defined as the ratio between the actual air-fuel ratio and the stoichiometric air-fuel ratio.

$$
\begin{aligned}
& f \mathrm{H}_{2}+(1-f) \mathrm{CH}_{4}+\lambda(2-1.5 f)\left(\mathrm{O}_{2}+3.76 \mathrm{~N}_{2}\right) \rightarrow \\
& \quad \rightarrow(1-f) \mathrm{CO}_{2}+(2-f) \mathrm{H}_{2} \mathrm{O}+3.76 \lambda(2-1.5 f) \mathrm{N}_{2}+(\lambda-1)(2-1.5 f) \mathrm{O}_{2}
\end{aligned}
$$

The heating value of the mixture has been calculated by equation (2), while volumetric composition of the exhaust (reaction products) has been worked out from equation (1).

$$
L H V_{\text {mix }}=f L H V\left(\mathrm{H}_{2}\right)+(1-f) \operatorname{LHV}\left(\mathrm{CH}_{4}\right)
$$

A case-study is reported in Table 2, for $25 \mathrm{~kW}$ of thermal load and an equivalence ratio of 1.25 (typical values for a domestic boiler [2,9]. Fuel, air and total mixture flow have 
been calculated for different $\mathrm{H}_{2}$ fractions; volumes are referred to pressure 1013 mbar and temperature $0^{\circ} \mathrm{C}$.

Table 2. Calculations for different $\mathrm{H}_{2}$ fraction (f), referred to $25 \mathrm{~kW}$ thermal load and $\lambda=1.25$.

\begin{tabular}{|c|c|c|c|c|c|c|}
\hline & $\mathbf{f}=\mathbf{0 \%}$ & $\mathbf{f = \mathbf { 2 0 } \%}$ & $\mathbf{f}=\mathbf{4 0 \%}$ & $\mathbf{f}=\mathbf{6 0 \%}$ & $\mathbf{f =} \mathbf{8 0 \%}$ & $\begin{array}{c}\mathbf{f}= \\
\mathbf{1 0 0} \%\end{array}$ \\
\hline Fuel flow $\left[\mathbf{m}^{\mathbf{3}} / \mathbf{h}\right]$ & 2.51 & 2.92 & 3.48 & 4.32 & 5.70 & 8.35 \\
\hline Air flow $\left[\mathbf{m}^{\mathbf{3}} / \mathbf{h}\right]$ & 29.86 & 29.51 & 29.02 & 28.30 & 27.12 & 24.84 \\
\hline Total reactants flow $\left[\mathbf{m}^{\mathbf{3}} / \mathbf{h}\right]$ & 32.37 & 32.42 & 32.50 & 32.62 & 32.81 & 33.19 \\
\hline $\mathbf{C O}_{2}$ exhaust $[\%]$ & 9.17 & 8.68 & 7.96 & 6.84 & 4.81 & 0.00 \\
\hline $\mathbf{O}_{2}$ exhaust $[\%]$ & 4.59 & 4.61 & 4.65 & 4.70 & 4.81 & 5.05 \\
\hline LHV $\left[\mathbf{M J} / \mathbf{m}^{3}\right]$ & 35.8 & 30.8 & 25.8 & 20.8 & 15.8 & 10.8 \\
\hline
\end{tabular}

\subsection{Regulatory context for gas fired boilers}

In the current European regulation [7], gases with $\mathrm{H}_{2}$ content are provided as limit gases for boilers nominally working with pure methane (thus, within the second family fuel gases, covering natural gas). Furthermore, even higher $\mathrm{H}_{2}$ percentages are considered for the first family fuel gases (covering manufactured gas, or "town gas"). Table 3 reports relevant characteristics for these standardised mixtures.

Table 3. Standardised fuel mixtures containing hydrogen [7].

\begin{tabular}{|c|c|c|c|c|}
\hline Gas family & Designation & Purpose & $\begin{array}{c}\text { Composition } \\
{[\% \mathbf{\% o l}]}\end{array}$ & $\begin{array}{c}\text { LHV } \\
{\left[\mathbf{M J} / \mathbf{m}^{3}\right]}\end{array}$ \\
\hline First & G110 & Reference gas & $26 \% \mathrm{CH}_{4}, 50 \% \mathrm{H}_{2}, 24 \% \mathrm{~N}_{2}$ & 13.95 \\
\hline First & G112 & Light back limit gas & $17 \% \mathrm{CH}_{4}, 59 \% \mathrm{H}_{2}, 24 \% \mathrm{~N}_{2}$ & 11.81 \\
\hline Second & G20 & Reference gas & $100 \% \mathrm{CH}_{4}$ & 34.02 \\
\hline Second & G222 & Light back limit gas & $77 \% \mathrm{CH}_{4}, 23 \% \mathrm{H}_{2}$ & 28.53 \\
\hline
\end{tabular}

\section{Impact of $\mathrm{H}_{2} \mathrm{NG}$ gases on premixed applications}

\subsection{Reference concept for domestic premixed device}

The Authors looked over several domestic boilers, both by directly examining real devices and by consulting documents from the boiler manufacturers, aiming to identify a typical layout valuable for analysing these heating appliances. This analysis is useful to investigate the impact of $\mathrm{H}_{2} \mathrm{NG}$ on the real components of devices. Notwithstanding several minor peculiarities and differences due to design choices, Fig. 1 can be reasonably taken as a reference for the components and operating principle of a domestic condensing boiler. The following paragraphs constitute an analysis of hydrogen addition effect on the main components, keeping the characteristics of current boilers as state of the art. 


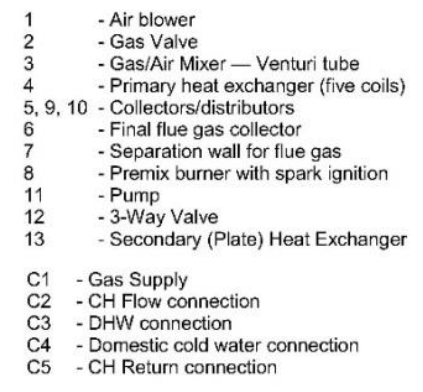

- Gas Valve

- Primary heat exchanger (five coils)

Premix burner with spark ignition

Pump

Way Valve

CH Flow connection

$\mathrm{CH}$ Return connection

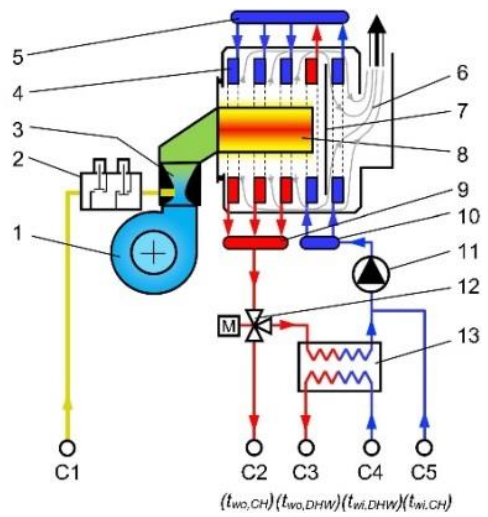

Fig. 1. Schematic of a condensing boiler system [8].

\subsection{Effect of hydrogen enrichment on fuel and air volumetric flows}

From Table 1 it can be noticed that, while increasing $\mathrm{H}_{2}$ content, the volumetric fuel flow increases significantly (3.3 times for pure $\mathrm{H}_{2}$ fuel than for pure $\mathrm{CH}_{4}$ ) to achieve the same thermal load, due to the decrease in volumetric LHV. Parallelly, the air flow keeps decreasing ( 0.8 times for pure $\mathrm{H}_{2}$ fuel than for pure $\mathrm{CH}_{4}$ ) due to the stoichiometry of reaction (1). As a result, the total reactants flow does not vary significantly (less than $4 \%$ variation between pure $\mathrm{H}_{2}$ fuel than for pure $\mathrm{CH}_{4}$ ). The adopted lambda value does not substantially affect the proportions involved in the foregoing reasoning. Referring to Fig. 1 and considering only the pressure drop related to the fluid flows, a dimensional resizing is due for the fuel side components, such as the gas valve, the gas piping and the gas/air mixer, when the $\mathrm{H}_{2}$ fraction is high. Referring to the data of Table 2, for example, the $\mathrm{f}=40 \%$ enrichment grade is likely to require already a re-design of the methane gas valve, since the nominal fuel flow is increased by about $+38 \%$. For the considered constant lambda value, instead, the components such as the blower and the manifold connecting the blower to the burner can be kept dimensionally equal whatever the $\mathrm{H}_{2}$ fraction is. A dedicated analysis, that cannot be limited to the bare pressure drop evaluation, has to be conducted for all the components whose functionality is strictly connected with the reactions occurring, such as the burner or the flame control systems.

\subsection{Effect of hydrogen enrichment on flashback and reactants ignition}

As highlighted by Table $1, \mathrm{H}_{2}$ has higher burning velocity, wider flammability range and lower ignition energy than methane. These aspects are transferred, even if not linearly, to the hydrogen enriched natural gas, thus a deepening on the potential effects is needed. Flashback phenomena and unwanted ignitions of reactants must be avoided to grant safety. The mixture ignition due to the flame speed exceeding the unburnt mixture speed (leading to the flame propagation upstream into the burner) has to be managed by a proper burner design, ensuring the unburnt speed to be always high enough. Premixed flame stabilization is a complex matter [9] involving heat transfer, fluid dynamics and chemical equilibrium, and the flashback threshold cannot be simply attributed to the mixture exit speed; nevertheless, a higher unburnt speed would help flashback avoidance. A premixed burner designed for hydrogen-enriched natural gas would thus require lower open area and lower 
flow channels diameter, to enhance quenching phenomena. It is well known that the value of $\lambda$ is very impacting on flashback phenomena, so a safety margin must be taken increasing the lambda value, but the implications on the air flow increase have to be evaluated in the terms of paragraph 4.2. Apart from the phenomenon described, attention has to be paid to the low ignition energy of hydrogen, which makes the reactants more susceptible to be ignited by unwanted energy sources, such as mechanical friction, high temperatures or electrical fields. Literature studies [10] state, for example, that the load applied on a steel surface with a rubbing tool is at least an order of magnitude lower to ignite hydrogen than methane. Other studies [6] suggest that the risk of ignition by electrostatic discharges significantly increases in methane mixtures containing more than $25 \% \mathrm{H}_{2}$, due to the fact that the ignition energy goes below $0.1 \mathrm{~mJ}$, typical threshold for corona discharges. Very little is available in literature about flashback on premixed devices fed with $\mathrm{H}_{2} \mathrm{NG}$, but looking to the data in Table 3 it can be concluded that at least up to $23 \% \mathrm{H}_{2}$, the current methane fired devices are able to operate without safety issues. With reference to the concept of Fig. 1, the implication of the findings exposed in this paragraph are involving all the components in contact with flammable mixture or in its proximity, i.e. the burner, the manifold connecting air/gas mixer to burner, the air/gas mixer itself and the blower. Although there is a gap in knowledge and a need for experiments on these topics, guidelines for these components include the reduction of frictional energy, electrostatic charging and wall temperatures.

\subsection{Effect of hydrogen enrichment on pollutant emissions}

Specific studies on $\mathrm{H}_{2}$ addition impact on pollutant emissions in premixed boilers are missing, even if in literature potentialities for $\mathrm{CO}$ and $\mathrm{NO}_{\mathrm{x}}$ reduction are mentioned [3]. About $\mathrm{CO}$ production, it is reasonable to expect a decrease with the $\mathrm{H}_{2}$ percentage increase, because of both the decrease of total carbon in the reactants and the increase in $\mathrm{OH}$ radicals, promoting the oxidation of $\mathrm{CO}$ to $\mathrm{CO}_{2}$. About $\mathrm{NO}_{\mathrm{x}}$ formation, $\mathrm{H}_{2}$ enrichment leads to higher combustion temperatures (triggering higher $\mathrm{NO}_{\mathrm{x}}$ production) but allows a stable combustion with higher $\lambda$ values than methane. The second effect could be managed in order to prevail, resulting in an overall lower $\mathrm{NO}_{\mathrm{x}}$ production. Finally, given that current gas fired devices nominally working with methane are already required to work with limit gases containing $\mathrm{H}_{2}$ (see Table 3), it can be deduced that at least a safe operation in terms of $\mathrm{CO}$ emission can be achieved with $\mathrm{H}_{2}$ content up to $23 \%$.

\subsection{Heating value and water condensate production for $\mathrm{H}_{2} \mathrm{NG}$ mixtures}

The impact of $\mathrm{H}_{2}$ addition on the maximum amount of condensable water and on the Higher and Lower Heating values is evaluated in this section.

Water vapour flow is calculated by equation (1), for the same conditions analysed in Table 2, while heating values are calculated basing on equation (2). Results are reported in Table 4. It can be noticed that the larger the $\mathrm{H}_{2}$ percentage is, the larger is the maximum recoverable condensation heat. This fact, coupled to the fuel flow needed, leads to an increase of the condensable water mass for a fixed thermal load (about $+70 \%$ for pure $\mathrm{H}_{2}$ than for pure $\mathrm{CH}_{4}$ ). Reminding the boiler concept of Fig. 1, for high $\mathrm{H}_{2}$ blending the heat exchanger design may need to be re-assessed to reach maximum efficiency, and the condensate discharge ducting need to be designed for a higher nominal water flow. 
Table 4. Calculations for different $\mathrm{H}_{2}$ fractions (f), referred to $25 \mathrm{~kW}$ thermal load and $\lambda=1.25$.

\begin{tabular}{|c|c|c|c|c|c|c|}
\hline & $\mathbf{f = 0 \%}$ & $\mathbf{f}=\mathbf{2 0 \%}$ & $\mathbf{f = 4 0 \%}$ & $\mathbf{f = 6 0 \%}$ & $\mathbf{f = 8 0 \%}$ & $\mathbf{f = 1 0 0 \%}$ \\
\hline Fuel flow $\left[\mathbf{m}^{\mathbf{3}} / \mathbf{h}\right]$ & 2.51 & 2.92 & 3.48 & 4.32 & 5.70 & 8.35 \\
\hline $\mathbf{L H V}\left[\mathbf{M J} / \mathbf{m}^{\mathbf{3}}\right]$ & 35.8 & 30.8 & 25.8 & 20.8 & 15.8 & 10.8 \\
\hline HHV/LHV [-] & 1.10 & 1.11 & 1.12 & 1.13 & 1.15 & 1.18 \\
\hline $\begin{array}{c}\text { Water vapour flow } \\
{\left[\mathbf{m}^{3} / \mathbf{h}\right]}\end{array}$ & 5.02 & 5.25 & 5.57 & 6.05 & 6.83 & 8.35 \\
\hline $\begin{array}{c}\text { Max condensable water } \\
{[\mathbf{k g} / \mathbf{h}]}\end{array}$ & 3.76 & 3.93 & 4.17 & 4.53 & 5.12 & 6.25 \\
\hline
\end{tabular}

\subsection{Effect of hydrogen enrichment on flame detection and controls}

Flame detection and combustion control systems are a complex and evolving technology, thus dedicated studies are needed to assess their suitability to be used in $\mathrm{H}_{2} \mathrm{NG}$ fired systems. The most used system in domestic boilers is based on ionization current, exploiting the electrical conductivity of the flame, indirectly measured by means of an electrode [6]. Experimental studies [11] showed that the detected ionization current is weakened when $\mathrm{H}_{2}$ is added to methane. Reasons for the decrease in the detected signal are a lower $\mathrm{CH}^{*}$ and $\mathrm{H}_{3} \mathrm{O}^{+}$radicals and a shift in the flame location, with respect to pure $\mathrm{CH}_{4}$ combustion. Since these control devices have been designed for hydrocarbons, the utilization with $\mathrm{H}_{2} \mathrm{NG}$ gases has to be assessed and may need a tuning.

\subsection{Materials selection}

Evidence is published to suggest that materials used for the distribution system can degrade due to the addition of $\mathrm{H}_{2}$ into the natural gas [6]. Moreover, the permeability of materials to the different fuels must be taken into account, since $\mathrm{H}_{2}$ molecule is smaller and more diffusive. Permeability must be evaluated together with the appropriateness of lifetime mechanical, physical and chemical properties. With regard to the boiler concept of Fig. 1, all the parts in contact with fuel and fuel/air mixture (gas pipe, sealings, ...) have to undergo leakage and lifetime evaluations. Referring, by way of example, to some of the currently used materials, polyethylene PE-100 is 4.6 times more permeable to $\mathrm{H}_{2}$ than to methane, and nylon PA-12 is 40 to 50 times more permeable to $\mathrm{H}_{2}$ than to methane [12]. Polymer PA-11 results to be an interesting solution for $\mathrm{H}_{2}$ transportation [13].

\section{Conclusions}

Hydrogen enriched natural gas will be used in the future to support the energy system decarbonisation. The impact on the whole gas fuel production to consumption chain is under investigation, and the end-user appliances are one very important point to be assessed. In this study a brief perspective is presented for the $\mathrm{H}_{2} \mathrm{NG}$, a model of the main $\mathrm{H}_{2} \mathrm{NG}$ mixture parameters is made, a reference premixed domestic boiler concept is identified, and an impact analysis on it is conducted. The novelty of this research is the focus on the design of real components of a typical condensing boiler. The need for re-design was found to be strongly dependent on the hydrogen blending percentage, and is particularly impacting for high $\mathrm{H}_{2}$ addition. To reach the same thermal load, the fuel flow with hydrogen blending is up to 3.3 times than with pure methane, and this has an 
implication on the design of the fuel-side components. Then, $\mathrm{H}_{2} \mathrm{NG}$ mixtures are particularly prone to unwanted ignition and flashing back in premixed devices. Especially on this last point, the burner design needs to be assessed. Another important point that has been highlighted is the consistent increase in the maximum condensable water flow, calculated to be up to $+70 \%$. Suggestions for the material selection, to be carefully conducted and supported by endurance testing, have been made to ensure the absence of leakages and to assess the degradation processes. Finally, further studies emerged to be necessary to characterize the impact of hydrogen on the pollutant emissions and on boiler efficiency (even if the expectation for premixed devices inclines to be positive). The analyses and modelling conducted within this study suggest that a moderate hydrogen enrichment of natural gas, up to about $20 \%$, can be sustained by the current premixed boilers with no need for substantial re-design. The main impacts of higher enrichment grades have been identified and guidelines for the re-design have been suggested. Future evolution of this research could involve a more detailed system modelling, a focus on a specific boiler component (such as the gas burner), and an experimental campaign on real applications.

\section{References}

1. European Commission, Energy Roadmap 2050 (Brussels, 2011)

2. F. Schiro, A. Stoppato, A. Benato, E3S Web of Conferences 22, 00154 (2017)

3. F. Schiro, A. Stoppato, A. Benato, Characterization of premixed flame blow-off downstream a multi-perforated burner (Proceeding of ECOS, 2018)

4. A. Lewandowska-Bernat, U. Desideri, Appl. Energy 228, 57-67 (2018)

5. B. Parkinson, M. Tabatabaei, Int. J. Hydrogen Energy 43, 2540-2555 (2018)

6. G. Lo Basso, B. Nastasi, Energy 123, 615-636 (2017)

7. B. Leibowicza, C. Lanhamb, Appl. Energy 130, 1311-1325 (2018)

8. F. Schiro, Research and development of premixed burners, with particular attention to the emissions, the modulation range and the ability to work efficiently with different fuel gases (PhD Thesis, University of Padova, Italy, 2017)

9. F. Schiro, A. Stoppato, Combust. Sci. Technol. 191, 453-471 (2019)

10. Publications Office of the European Union, EU Reference Scenario 2016 - Energy, transport and GHG emissions - Trends to 2050 (2016)

11. Health and Safety Laboratory, Injecting hydrogen into the gas network - a literature research-Research Report 1047 (2015)

12. EN 437, Test gases, test pressures, appliance categories and gas appliance types (2009)

13. D. T. Bălănescu, V. M. Homutescu, Appl. Therm. Eng. 143, 48-58 (2018)

14. C. Prousta, S. Hawksworth, J. Loss Prev. Process Ind. 20, 349-365 (2007)

15. Danish Gas Technology Centre, Combustion control in domestic gas appliances (2014)

16. P. N. Kowski, Impact of hydrogen admixture on installed gas appliances (2012)

17. M. Klopfer, P.Berne, E. Espuche, Oil \& Gas Science and Technology 70, 305-315 (2015) 